\title{
Patient-rated level of discomfort during assessment with point-of-care ultrasonography
}

\author{
Christian B Laursen ${ }^{1 *}$, Erik Sloth ${ }^{2}$, Annmarie T Lassen ${ }^{3}$, Jess Lambrechtsen ${ }^{4}$, Daniel P Henriksen ${ }^{4,5}$, Finn Rasmussen ${ }^{6}$ \\ From 6th Danish Emergency Medicine Conference \\ Odense, Denmark. 20-21 November 2014
}

\section{Introduction}

This study aimed to assess the patient-rated level of discomfort during point-of-care ultrasonography of the heart, lungs, and deep veins in a population of patients admitted to an emergency department with respiratory symptoms and to what extent the patients would accept being assessed by the use of point-of-care ultrasonography if they had to be examined for possible disease.

\section{Methods}

A questionnaire-based observational study was conducted in an emergency department. Inclusion criteria were one or more of the following: respiratory rate $>20$ /minute, oxygen saturation $<95 \%$, oxygen therapy initiated, dyspnoea, cough or chest pain. Patients were examined by the use of point-of-care ultrasonography of the heart, lungs, and deep veins. Patient-rated level of discomfort and acceptance were assessed using a standardised questionnaire.

\section{Results}

A total of 1,130 patients were assessed for eligibility, of which 299 (26.5\%) patients were included. 26 patients was not able to fill out the questionnaire and 2 patients withdrew informed consent, leaving 271 patients available for study analysis. The median duration of the sonographic examinations was 12 minutes (IQR 11-13, range 9-23). The median patient-rated level of discomfort for all three types of sonography was 1 (IQR 1-1, range 1-8) on a scale from 1 to 10. All but one patient (99.6\% (95\% CI: 98.9$100 \%)$ ), would accept being examined by the use of pointof-care ultrasonography as a part of routine emergency department diagnostics.

\footnotetext{
* Correspondence: christian.b.laursen@rsyd.dk

'Department of Respiratory Medicine, OUH Odense University Hospital, Odense, Denmark

Full list of author information is available at the end of the article
}

\section{Conclusion}

The patient-rated level of discomfort during point-of-care ultrasonography of the heart, lungs, and deep veins is very low and the vast majority of patients would accept being assessed by the use of point-of-care ultrasonography if the patients once again had to be examined for possible disease.

\section{Authors' details}

${ }^{1}$ Department of Respiratory Medicine, OUH Odense University Hospital,

Odense, Denmark. ${ }^{2}$ Department of Anesthesia and Intensive Care, Aarhus University Hospital, Skejby, Denmark. ${ }^{3}$ Department of Emergency Medicine, OUH Odense University Hospital, Odense, Denmark. ${ }^{4}$ Department of Medicine, OUH Odense University Hospital, Svendborg, Denmark. ${ }^{5}$ Institute of Clinical Research, University of Southern Denmark, Odense, Denmark. ${ }^{6}$ Department of Allergy and Respiratory Medicine, Near East University Hospital, Nicosia, North Cyprus, Mersin 10, Turkey.

Published: 16 July 2015

doi:10.1186/1757-7241-23-S1-A17

Cite this article as: Laursen et al:: Patient-rated level of discomfort during assessment with point-of-care ultrasonography. Scandinavian Journal of Trauma, Resuscitation and Emergency Medicine 2015 23(Suppl 1): A17.

Submit your next manuscript to BioMed Central and take full advantage of:

- Convenient online submission

- Thorough peer review

- No space constraints or color figure charges

- Immediate publication on acceptance

- Inclusion in PubMed, CAS, Scopus and Google Scholar

- Research which is freely available for redistribution 